\title{
Reactivities of Cyclic Monomers in Cationic Copolymerizations. Nucleophilic Coordination and Ionic Ring-Opening of the Bond
}

\author{
Tsutomu KagiYa, Yūzō Sumida, and Tokuji Inoue* \\ Faculty of Engineering, Kyoto University, Sakyo-ku, Kyoto, Japan.
}

(Received December 5, 1969)

\begin{abstract}
In this study an empirical calculation of the relative reactivities of cyclic ethers, formals, and esters in cationic copolymerizations has been achieved. It is postulated that the apparent propagation reaction consists of two elementary reactions of the nucleophilic coordination of cyclic monomers to a growing cation and of the ionic ring-opening and addition of the broken bond. The former is an equilibrium reaction and its equilibrium constant has been evaluated as $K_{D}$ (or the free energy change, $\Delta G_{D}$ ) of the intermolecular complex formed between the monomer and the deuterium atom of methanol- $d$ as a cation model. The reactivity of the latter has been discussed using the method of activation energy evaluation employing the Morse potential energy function, and the rate constant has been approximately estimated with the radical dissociation energy, $D_{i}$, of the broken bond. The available experimental data on the reactivities of cyclic monomers are discussed in detail by using these energetic terms. The following empirical formula has been derived to represent the relative reactivities of cyclic ethers
\end{abstract}

$$
\log \frac{1}{r_{1}}=-\frac{1}{2.3 R T}\left(2.50 \Delta \Delta G_{D}+0.10 \Delta D_{i}(\mathrm{C}-\mathrm{O})\right)
$$

where $\Delta$ is the difference from monomer 2 to 1 . The treatment proposed is useful for the evaluation of the monomer reactivities of various cyclic ethers in cationic copolymerizations.

\section{KEY WORDS Reactivity / Cyclic Ether / Cationic Copolymeriza- tion / Nucleophilic Coordination / Ring Opening / Methanol-d / Activation Energy / Morse Function / Dissociation Energy / C-O Bond /}

In recent years, many studies have been made on the cationic copolymerizations of cyclic ethers, ${ }^{1-3}$ formals, ${ }^{4}$ esters, ${ }^{5,6}$ and imines ${ }^{7,8}$ and sufficient reliable copolymerization parameters have been collected. On the basis of these valuable experimental data, Iwatsuki et al. ${ }^{1}$ have indicated that the relative reactivities of cyclic ethers in cationic copolymerizations are in good correlation with their basicities. Since then, many researchers have investigated the relation between the structures and the reactivities of cyclic ethers; Aoki et al. ${ }^{9}$ made a study which aimed at relating the ionic reactivities of cyclic ethers to two factors of the ring strain and the basicity.

\footnotetext{
* Present address: Ube Industries Co. Ltd., Ichihara Chiba, Japan.
}

On the other hand, the present authors ${ }^{10}$ have studied the energetic consideration of catalytic polymerizations of various vinyl monomers and found the quantitative correlation between the monomer reactivities and the catalytic activities.

Moreover, the authors ${ }^{11}$ have investigated the nucleophilic or electrophilic coordination of various organic compounds to methanol-d or acetophenone by means of an infrared spectrophotometer and presented a new measure of the electron-donating powers and the electron-accepting powers of the compounds.

This work was done with the object of presenting an empirical formula for the evaluation of the relative reactivities of cyclic monomers, especially cyclic ethers, in cationic copolymerizations. The propriety of the formula obtained 
is discussed in connection with the observed values.

\section{THEORETICAL}

As has been described in previous papers, ${ }^{10,12}$ we stand also in this paper on the assumption that the apparent propagation reaction in cationic copolymerization of various cyclic monomer is divided into two elementary reactions; the first is the fast formation reaction of the intermolecular complex formed by the nucleophilic coordination between the monomer and the growing cation, and the second is the slow reaction of the ionic ring opening and addition.

According to this postulation, the propagation reaction in cationic copolymerization which is caused by the same catalyst in the same solvent is illustrated by the following scheme; as an example, we considered the cationic copolymerization of the growing cation $1\left(-\mathrm{C}_{1}^{+} \mathrm{D}^{-}\right)$with the cyclic ethers 1 and $2\left(\mathrm{M}_{1}: \mathrm{OM}_{1}, \mathrm{M}_{2}: \mathrm{OM}_{2}\right)$ :

$$
\begin{aligned}
& -\mathrm{C}_{1}{ }^{+} \mathrm{D}^{-}+\widehat{\mathrm{OM}}_{1} \stackrel{K_{11}}{=} \\
& -\mathrm{C}_{1}+\overbrace{1}^{\mathrm{M}_{1}} \mathrm{D}^{-} \stackrel{k_{11}}{\longrightarrow}-\mathrm{C}_{1}{ }^{+} \mathrm{D}^{-} \\
& -\mathrm{C}_{1}{ }^{+} \mathrm{D}^{-}+\widehat{\mathrm{OM}}_{2} \stackrel{K_{12}}{\rightleftarrows} \\
& -\mathrm{C}_{1}+\overbrace{2} \mathrm{D}^{-} \stackrel{k_{12}}{\longrightarrow}-\mathrm{C}_{2}{ }^{+} \mathrm{D}^{-}
\end{aligned}
$$

where $K$ and $k$ are respectively the equilibrium constant of the coordination reaction and the rate constant of the ionic ring-opening and addition reaction.

From reaction schemes 1 and 2 , the relative reactivity, $\log \left(1 / r_{1}\right)$, can be expressed as

$$
\log \frac{1}{r_{1}}=\log \frac{K_{12}}{K_{11}}+\log \frac{k_{12}}{k_{11}}
$$

Eq. 3 shows that the relative reactivity is quantitatively evaluated by two factors of the nucleophilic coordination power of monomer and of the facility of the ionic ring-opening and addition.

\section{The Nucleophilic Coordination Reaction}

Using the same treatment as described previously, ${ }^{12}$ we employed the nucleophilic equilibrium reaction of monomer with methanol- $d$, as a model of the nucleophilic coordination reaction of the first stage.

$$
\mathrm{CH}_{3} \mathrm{O} \stackrel{\partial^{-}}{\mathrm{D}} \stackrel{\partial^{+}}{\mathrm{OM}} \stackrel{K_{D}}{=} \mathrm{CH}_{3} \stackrel{\partial^{-}}{\mathrm{O}} \stackrel{\partial^{+}}{\mathrm{D}} \stackrel{\mathrm{OM}}{\mathrm{M}}
$$

If we consider that the $K$ values in Eq. 3 are related to the $K_{D}$ values by a linear-free-energy relationship, we have

$$
\log \frac{K_{12}}{K_{11}}=\phi_{1} \log \frac{K_{D 2}}{K_{D 1}}
$$

in which $\phi_{1}$ is a constant characteristic of the electrophilic character of cation 1 .

In the copolymerization in which the effect of the ionic ring-opening and addition on the monomer reactivity is nearly constant, the independence of the kind of cyclic monomers in Eq. 3 can be simplified as

$$
\log \frac{1}{r_{1}}=\phi_{1} \log \frac{K_{D 2}}{K_{D 1}}
$$

Therefore, in such a copolymerization system, the electrophilic parameter of growing cation is given with the slope of a straight line through an origin between $\log \left(1 / r_{1}\right)$ and $\log \left(K_{D 2} / K_{D 1}\right)$.

\section{The Ionic Ring-Opening and Addition Reactions}

We discuss the reactivity of cyclic monomer in the ionic ring-opening and addition reaction using the same method of activation energy evaluation as described in detail in the radical substitution, ${ }^{13,14}$ in the radical addition, ${ }^{15}$ and in the ionic $\pi$-cleavage and addition reactions. ${ }^{12}$ It was assumed that the ionic ring-opening and addition reaction proceeds through three models $((a),(b)$, and (c)) in the transition state

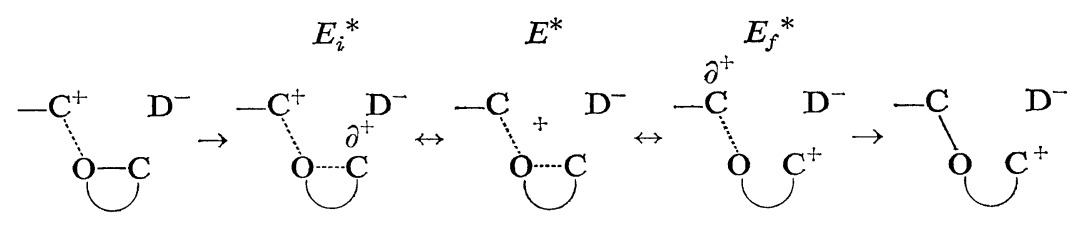

(b) (c) 
where the potential energy in the transition state is equivalent, $E_{i}{ }^{*}=E^{*}=E_{f}{ }^{*}$, and is localized on the bond broken in the initial monomer in (a), (C-O bond in cyclic ether), and on the bond formed in the final product in (c), (C-O bond), and is delocalized on the two bonds broken and formed in (b), (C---O---C bonds).

The potential energy curve of the radical dissociation of a $\sigma$ bond in a polyatomic molecule can be expressed by the Morse function. ${ }^{13,16}$ We assumed this concept could be extended to that of the ionic dissociation of the $\sigma$ bond. On the basis of the assumption, the potential-energy change of the bond broken from the ground state to the transition state (a) is expressed by

$$
E_{i}=D_{i}{ }^{\prime}\left(1-e^{-a_{i}{ }^{\prime \prime}\left(r_{i}-r_{i} 0\right)}\right)^{2}-D_{i}{ }^{\prime}
$$

Similarly, that of the bond formed from the transition state (c) to the product is

$$
E_{f}=D_{f}^{\prime}\left(1-e^{-a f^{\prime \prime}\left(r_{f}-r_{f} 0\right)}\right)^{2}-D_{f}^{\prime}
$$

In Eqs. 8 and 9, the subscripts $i$ and $f$ are the initial and the final systems, respectively; $E$, the potential energy along the reaction path; $r$, the bond distance between reacting atoms in the same molecule; $r^{0}$, the equilibrium distance of the bond; $a^{\prime \prime}$, the constant corresponding to the Morse one, and $D^{\prime}$ is the cationic dissociation energy of the bond, that is, the sum of the radical dissociation energy of the bond, $D$, and the ionization potential, $I P(-\mathrm{C})$, of the growing carbon radical for the final system or that, $I P(C)$, of the carbon radical in the ring-opened form of monomer for the initial system, i.e., $D_{i}{ }^{\prime}=$ $D_{i}+I P(\mathrm{C})$ and $D_{f}{ }^{\prime}=D_{f}+I P(-\mathrm{C})$.

From the combination of Eqs. 8 and 9 , in the transition state, we obtained

$$
\begin{aligned}
& a_{f}{ }^{\prime \prime} \Delta r_{f}{ }^{*}-a_{i}{ }^{\prime \prime} \Delta r_{i}{ }^{*} \\
& =-\ln \left(1-\sqrt{\frac{D_{f}^{\prime}+E_{f}{ }^{*}}{D_{f}^{\prime}}}\right) /\left(1-\sqrt{\frac{D_{i}^{\prime}+E_{i}^{*}}{D_{i}^{\prime}}}\right) \\
& =-\ln \left(1-\sqrt{\frac{E_{a}+\Delta H}{D_{f^{\prime}}}}\right) /\left(1-\sqrt{\frac{E_{a}}{D_{i}^{\prime}}}\right) \quad(10)
\end{aligned}
$$

where $E_{a}$ is the activation energy of the reaction, and $\Delta H$ the reaction heat, and $\Delta r_{i}{ }^{*}, \Delta r_{f}{ }^{*}$ are equal to $\left(r_{i}{ }^{*}-r_{i}{ }^{0}\right),\left(r_{f}{ }^{*}-r_{f}{ }^{0}\right)$, respectively.

If the quantitative linear correlation between the $\left(a_{f}{ }^{\prime \prime} \Delta r_{f}{ }^{*}-a_{i}{ }^{\prime \prime} \Delta r_{i}{ }^{*}\right)$ and the reaction heat
$\Delta H$ holds, not only in the radical substitution ${ }^{13}$ and addition reactions ${ }^{15}$ but also in the ionic reactions, though it cannot be empirically confirmed, we can introduce the following relation into Eq. 10

$$
a_{f}{ }^{\prime \prime} \Delta r_{f}{ }^{*}-a_{i}{ }^{\prime \prime} \Delta r_{i}{ }^{*}=\omega^{\prime \prime} \Delta H
$$

where $\omega^{\prime \prime}$ is a constant in a series of ionic reactions.

By substituting the relation 11 into Eqs. 8 and 9 , as the formula for evaluating the activation energies, we have

$$
E_{a}=\frac{D_{i}^{\prime}\left(\left(1-2 \chi^{\prime}\right) D_{f}^{\prime}+\chi^{\prime 2} D_{i}^{\prime}\right)^{2}}{\left(D_{f}^{\prime}-\chi^{\prime 2} D_{i}^{\prime}\right)^{2}}
$$

where $\chi^{\prime}=\exp \left(\omega^{\prime \prime} \Delta H\right)$.

As the first approximation of Eq. 12,

$$
E_{a}=D_{i}{ }^{\prime}-\gamma^{\prime} D_{i}{ }^{\prime} D_{f}{ }^{\prime}=\left(1-\gamma^{\prime} D_{f}{ }^{\prime}\right) D_{i}{ }^{\prime}
$$

By using the assumptions that the activation energy follows the Arrhenius equation and its frequency factor is a constant, the relative rate constant of the ionic ring-opening and addition reaction should be expressed by

$$
\begin{aligned}
\log \frac{k_{12}}{k_{11}}= & -\frac{1}{2.3 R T}\left(E_{a(1,2)}-E_{a(1,1)}\right) \\
= & -\frac{1}{2.3 R T}\left(\left(1-\gamma^{\prime} D_{f(1,2)}^{\prime}\right) D_{i(2)}^{\prime}\right. \\
& \left.-\left(1-\gamma^{\prime} D_{f(1,1)}^{\prime}\right) D_{i(1)}^{\prime}\right)
\end{aligned}
$$

In Eq. 14, the cationic dissociation energy $D_{f(1,2)}^{\prime}\left(=D_{f(1,2)}+I P\left(-C_{1}\right)\right)$ can be regarded as nearly equal to that $D_{f(1,1)}^{\prime}\left(=D_{f(1,1)}+\right.$ $\left.I P\left(-\mathrm{C}_{1}\right)\right)$, because the radical dissociation energy $D_{f(1,2)}$ or $D_{f(1,1)}$ is taken as a constant depending only on the chemical structure of monomers, for example, $80 \pm 5 \mathrm{kcal} / \mathrm{mol}$ for $D_{f}$ of cycloalkanes and $75 \pm 5 \mathrm{kcal} / \mathrm{mol}$ for $D_{f}$ of cyclic ethers. Then, Eq. 14 can be rewritten by

$$
\log \frac{k_{12}}{k_{11}}=-\frac{\delta^{\prime}}{2.3 R T}\left(\Delta D_{i}+\Delta I P_{i}\right)
$$

where $\delta^{\prime}$ is related to $D_{f}^{\prime}$ by $\delta^{\prime}=1-\gamma^{\prime} D_{f}^{\prime}$. Eq. 15 is a formula expressing the relative reactivity of monomer in the ring-opening and addition reaction with two characteristic values of the radical bond-dissociation energy and the ionization potential.

In order to estimate the contribution of two 
energetic terms on the reactivity, the radical bond-dissociation energies of typical cyclic ethers ${ }^{17}$ and the ionization potentials of alkyl radicals analogous in chemical structures to the ring-opened forms of ethers are listed in Table I. It is apparent that the radical bond-dissocia-

Table I. Radical C-O bond-dissociation energies of cyclic ethers and ionization potentials of corresponding alkyl radicals

\begin{tabular}{lclc}
\hline Cyclic ether & $\begin{array}{c}D(\mathrm{C}-\mathrm{O})^{\mathrm{a}} \\
(\mathrm{kcal} / \mathrm{mol})\end{array}$ & Alkyl radical & $\begin{array}{c}I P \\
(\mathrm{eV})\end{array}$ \\
\hline Ethylene oxide & 47.7 & Ethyl & 8.78 \\
Oxetane & $48.3^{\mathrm{b}}$ & Propyl & 8.69 \\
Tetrahydrofuran & 68.6 & $n$-Butyl & 8.64 \\
Tetrahydropyran & 71.2 & $n$-Pentyl & 8.61 \\
\hline
\end{tabular}

a Data in ref. 17.

b An approximate value evaluated from Figure 1.

tion energies vary remarkably from $47.7 \mathrm{kcal} /$ mol for ethylene oxide of the three-membered ring to $71.2 \mathrm{kcal} / \mathrm{mol}$ for tetrahydropyran of the six-membered ring, whereas the ionization potentials vary only slightly. This fact is an opposite result to that the in $\pi$-bond cleavage and addition reaction of vinyl monomer to growing cation; ${ }^{12}$ that is, in the latter case, the radical dissociation energies of $\pi$ bonds can be regarded

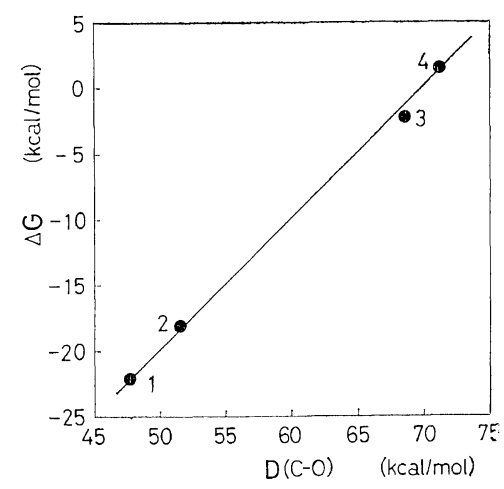

Figure 1. Relation between the $\mathrm{C}-\mathrm{O}$ bonddissociation energies of cyclic ethers and the free energy changes of polymerizations of the corresponding cycloalkanes: 1 , ethylene oxide-cyclopropane; 2 , propylene oxide-2-methlcyclopropane; 3, tetrahydrofuran-cycloropentane; 4, tetrahydropyrancyclohexane. as constant, whereas the ionization potentials of $\alpha$-carbon radicals are markedly affected by the kind of substituent groups adjacent to vinyl groups.

On the basis of the above consideration, the second term of Eq. 15 can be virtually neglected:

$$
\log \frac{k_{12}}{k_{11}}=-\frac{\delta^{\prime}}{2.3 R T} \Delta D_{i}
$$

Thus it is noted that the radical bond-dissociation term is the more important factor in the cationic ring-opening and addition reaction than the ionization term, in spite of ionic reactions.

From the combination of Eqs. 3, 5, and 16, the relative reactivity can be expressed as a function of two energetic values of the nucleophilic coordination power of monomer and the radical bond-dissociation energy of broken bond, as follows.

Table II. Radical C-O bond-dissociation energies of cyclic ethers and radical $\mathrm{C}-\mathrm{C}$ bond-dissociation energies and free-energy changes of polymerizations of corresponding cycloalkanes

\begin{tabular}{|c|c|c|c|}
\hline$\alpha$ Substituent & $\begin{array}{c}D(\mathrm{C}-\mathrm{O}) \\
(\mathrm{kcal} / \mathrm{mol})\end{array}$ & $\begin{array}{c}D(\mathrm{C}-\mathrm{C}) \\
(\mathrm{kcal} / \mathrm{mol}\end{array}$ & $\begin{array}{c}\Delta G \\
(\mathrm{kcal} / \mathrm{mol}\end{array}$ \\
\hline \multicolumn{4}{|l|}{ 3-Membered ring } \\
\hline $\mathrm{H}$ & 47.7 & 57.0 & -22.1 \\
\hline $\mathrm{CH}_{3}$ & 51.5 & & -18.1 \\
\hline $\mathrm{C}_{2} \mathrm{H}_{5}$ & $51.5^{\mathrm{a}}$ & & \\
\hline $\mathrm{C}_{6} \mathrm{H}_{5} \mathrm{CH}_{2}$ & $51.5^{a}$ & & \\
\hline $\mathrm{CH}_{2} \mathrm{Cl}$ & $55.0^{\mathrm{c}}$ & & \\
\hline \multicolumn{4}{|l|}{ 4-Membered ring } \\
\hline $\mathrm{H}$ & $48.3^{b}$ & 64.0 & -21.5 \\
\hline $\mathrm{CH}_{3}$ & $52.1^{b}$ & & -17.7 \\
\hline 3, 3-Bis- $\mathrm{CH}_{2} \mathrm{Cl}^{\mathrm{d}}$ & $63.0^{\mathrm{c}}$ & & \\
\hline \multicolumn{4}{|l|}{ 5-Membered ring } \\
\hline $\mathrm{H}$ & 68.6 & 80.0 & -2.2 \\
\hline $\mathrm{CH}_{3}$ & $71.3^{b}$ & & 1.5 \\
\hline \multicolumn{4}{|l|}{ 6-Membered ring } \\
\hline $\mathrm{H}$ & 71.2 & 87.0 & 1.4 \\
\hline $\mathrm{CH}_{3}$ & $75.4^{b}$ & & 5.5 \\
\hline
\end{tabular}

a Value of propylene oxide.

b Values evaluated from the linear relation in Figure 1.

c Values evaluated on the basis of the assumption that $D(\mathrm{C}-\mathrm{O})$ increases $7.3 \mathrm{kcal} / \mathrm{mol}$ by introducing one chloromethyl group.

d $\beta$ Substituent. 


$$
\log \frac{1}{r_{1}}=\phi_{1} \log \frac{K_{D 2}}{K_{D 1}}-\frac{\delta^{\prime}}{2.3 R T} \Delta D_{i}
$$

By using the thermodynamic relation, $2.3 R T \log K_{D}=-\Delta G_{D}$, we have

$$
\log \frac{1}{r_{1}}=-\frac{1}{2.3 R T}\left(\phi_{1} \Delta \Delta G_{D}+\delta^{\prime} \Delta D_{i}\right)
$$

where $\Delta \Delta G_{D}$ is the increase in the free energy changes between two monomers.
The Radical Dissociation Energy of the $\mathrm{C}-\mathrm{O}$ Bond of Cyclic Ether

In order to analyze the relative reactivities with the use of Eq. 17 or 18, we have to know the radical dissociation energies of bonds which might be broken in cationic polymerizations of unsubstituted and substituted cyclic monomers. Little information has, however, been reported on the radical bond-dissociation energies of various cyclic monomers, but not on

Table III. Relative reactivities of cyclic monomers in cationic copolymerizations

\begin{tabular}{|c|c|c|c|c|c|}
\hline Monomer $\left(\mathrm{M}_{2}\right)$ & Solvent & $r_{1}$ & $r_{2}$ & $\log \left(1 / r_{1}\right)$ & $\underset{(l / \mathrm{mol})}{\log K_{D}}$ \\
\hline \multicolumn{6}{|l|}{$\mathbf{M}_{1}$, 3, 3-Bischloromethyloxetane 9} \\
\hline Ethylene oxide & $\mathrm{CH}_{2} \mathrm{Cl}_{2}$ & 0.5 & 0.2 & 0.301 & -0.389 \\
\hline Propylene oxide & $\mathrm{CH}_{2} \mathrm{Cl}_{2}$ & 0.3 & 0.65 & 0.523 & -0.319 \\
\hline 1-Butylene oxide & $\mathrm{CH}_{2} \mathrm{Cl}_{2}$ & 0.3 & 2.0 & 0.523 & -0.292 \\
\hline Epichlorohydrin & $\mathrm{CH}_{2} \mathrm{Cl}_{2}$ & 2.5 & 0.4 & -0.398 & -0.526 \\
\hline Styrene oxide & $\mathrm{CH}_{2} \mathrm{Cl}_{2}$ & 0.8 & 0.8 & 0.097 & -0.433 \\
\hline 3-Phenylpropylene oxide & $\mathrm{CH}_{2} \mathrm{Cl}_{2}$ & 0.45 & 1.1 & 0.347 & -0.389 \\
\hline Oxetane & $\mathrm{CH}_{2} \mathrm{Cl}_{2}$ & 0.01 & 10.8 & 2.00 & 0.215 \\
\hline 2-Methyloxetane & $\mathrm{CH}_{2} \mathrm{Cl}_{2}$ & 0.04 & 3.4 & 1.40 & 0.265 \\
\hline 3, 3-Bischloromethyloxetane & $\mathrm{CH}_{2} \mathrm{Cl}_{2}$ & 1.00 & 1.00 & 0 & -0.085 \\
\hline Tetrahydrofuran & $\mathrm{CH}_{2} \mathrm{Cl}_{2}$ & 0.82 & 1.00 & 0.086 & 0.042 \\
\hline 2-Methyltetrahydrofuran & $\mathrm{CH}_{2} \mathrm{Cl}_{2}$ & - & - & -0.114 & 0.081 \\
\hline Tetrahydropyran & $\mathrm{CH}_{2} \mathrm{Cl}_{2}$ & 1.5 & - & -0.180 & 0.071 \\
\hline 2-Methyltetrahydropyran & $\mathrm{CH}_{2} \mathrm{Cl}_{2}$ & 7.2 & 0 & -0.854 & 0.081 \\
\hline \multicolumn{6}{|l|}{$\mathbf{M}_{1}$, Tetrahydrofuran ${ }^{20}$} \\
\hline Epichlorohydrin & - & 3.85 & 0.0 & -0.585 & -0.526 \\
\hline 3, 3-Bischloromethyloxetane & - & 1.00 & 0.82 & 0 & -0.085 \\
\hline Tetrahydrofuran & - & 1.00 & 1.00 & 0 & 0.042 \\
\hline \multicolumn{6}{|l|}{$M_{1}, 1,3-$ Dioxolane 20} \\
\hline Oxetane & - & 0.01 & 180 & 2.00 & 0.215 \\
\hline 3, 3-Bischloromethyloxetane & - & 0.28 & 1.7 & 0.553 & -0.085 \\
\hline Tetrahydrofuran & - & 0.25 & 28 & 0.602 & 0.042 \\
\hline 1,3-Dioxolane & - & 1.00 & 1.00 & 0 & -0.333 \\
\hline 4-Chloromethyl-1, 3-dioxolane & - & 10.7 & 0.18 & -1.03 & -0.225 \\
\hline \multicolumn{6}{|l|}{$\mathbf{M}_{1}$, 4-Chloromethyl-1, 3-dioxolane } \\
\hline 1, 3-Dioxolane & - & 0.18 & 10.7 & 0.745 & -0.333 \\
\hline 4-Methyl-1, 3-dioxolane & - & 0.45 & 3.3 & 0.347 & -0.347 \\
\hline 4-Chloromethyl-1, 3-dioxolane & - & 1.00 & 1.00 & 0 & -0.558 \\
\hline Tetramethylene formal & - & 0.12 & 14.2 & 0.921 & -0.154 \\
\hline 1, 3, 6-Trioxocane & - & 0.08 & 75 & 1.097 & -0.096 \\
\hline \multicolumn{6}{|l|}{$\mathbf{M}_{1}, 3,3$-Bischloromethyloxetane ${ }^{5}$} \\
\hline$\beta$-Propiolactone & $\mathrm{C}_{6} \mathrm{H}_{5} \mathrm{CH}_{3}$ & 16.7 & 0.15 & -1.223 & -0.714 \\
\hline$\beta$-Methyl- $\beta$-propiolactone & $\mathrm{C}_{6} \mathrm{H}_{5} \mathrm{CH}_{3}$ & 11.9 & - & -1.076 & -0.661 \\
\hline$\beta$-Dimethyl- $\beta$-propiolactone & $\mathrm{C}_{6} \mathrm{H}_{5} \mathrm{CH}_{3}$ & 7.24 & - & -0.860 & -0.592 \\
\hline$\gamma$-Butyrolactone & $\mathrm{C}_{6} \mathrm{H}_{5} \mathrm{CH}_{3}$ & 1.4 & 0.04 & -0.146 & -0.227 \\
\hline$\delta$-Valerolactone & $\mathrm{C}_{6} \mathrm{H}_{5} \mathrm{CH}_{3}$ & 0.20 & 0 & 0.699 & -0.041 \\
\hline$\varepsilon$-Caprolactone & $\mathrm{C}_{6} \mathrm{H}_{5} \mathrm{CH}_{3}$ & 0.24 & 0.44 & 0.620 & -0.063 \\
\hline
\end{tabular}
catalyzed by $\mathrm{BF}_{3} \cdot \mathrm{O}\left(\mathrm{C}_{2} \mathrm{H}_{5}\right)_{2}$ at $0^{\circ} \mathrm{C}$ 
those of some unsubstituted cyclic ethers ${ }^{17}$ and cycloalkanes. ${ }^{18}$

In order to evaluate the unknown radical bond-dissociation energies, $D(\mathrm{C}-\mathrm{O})$, of cyclic ethers, we used the free energy changes of polymerizations, $\Delta G$, of cycloalkanes analogous to cyclic ethers in chemical structures. ${ }^{19}$ Figure 1 shows a relation between $D(\mathrm{C}-\mathrm{O})$ and $\Delta G$. From this good linear relation with the slope of $45^{\circ}$, the unknown $D(\mathrm{C}-\mathrm{O})$ values have been approximately evaluated and listed in Table II. In Table II, as will be described in the following chapter, we take the $D(\mathrm{C}-\mathrm{O})$ of 3,3 -bischloromethyloxetane as $63.0 \mathrm{kcal} / \mathrm{mol}$ and that of epichlorohydrin as $55.0 \mathrm{kcal} / \mathrm{mol}$. It is shown in Table II that the $D(\mathrm{C}-\mathrm{O})$ value increases about $4.0 \mathrm{kcal} / \mathrm{mol}$ and $7.3 \mathrm{kcal} / \mathrm{mol}$ by introducing methyl and chloromethyl groups, respectively.

\section{INTERPRETATION OF EXPERIMENTAL DATA}

The relative reactivities of various cyclic ethers, formals, and lactones toward various polymer cations are summarized in Table III, together with the nucleophilic equilibrium constants to methanol-d. ${ }^{11}$

\section{The Cationic Copolymerizations of Cyclic Ethers}

The 3,3-Bischloromethyloxetane $\left(M_{1}\right)$-Cyclic

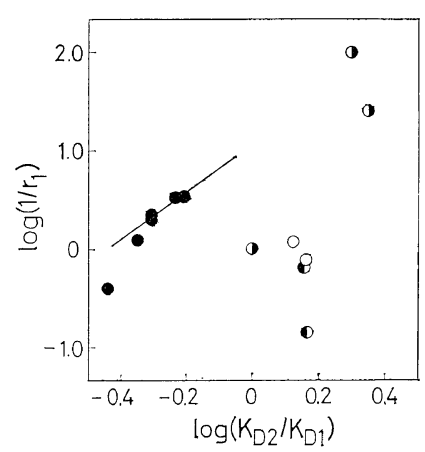

Figure 2. Relation between $\log \left(1 / r_{1}\right)$ in cationic copolymerizations of cyclic ethers $\left(\mathbf{M}_{2}\right)$-3, 3-bischloromethyloxetane $\left(\mathbf{M}_{1}\right)$ and $\log \left(K_{D 2} / K_{D 1}\right)$ of cyclic ethers: $\bullet$, three-membered ring; $O$, fourmembered ring; $O$, five-membered ring; $O$, sixmembered ring. A straight line indicates a slope of 2.50 .
Ethers $\left(M_{2}\right)$. We plotted, according to Eq. 17, $\log \left(1 / r_{1}\right)$ against $\log \left(K_{D 2} / K_{D 1}\right)$ (or $\left.\Delta \Delta G_{D}\right)$ of monomers (Figure 2). It can be observed in Figure 2 that a straight line is drawn for four points of substituted ethylene oxides having unconjugated groups $\left(\mathrm{H}, \mathrm{CH}_{3}, \mathrm{C}_{2} \mathrm{H}_{5}, \mathrm{C}_{6} \mathrm{H}_{5} \mathrm{CH}_{2}\right)$ whose $D_{i}(\mathrm{C}-\mathrm{O})$ can be regarded as constant, and that the value $\left(\phi_{1}=2.50\right)$ of the slope is more than unity. The latter result is considered to mean that the electrophilic character of poly(BCMO) cation is 2.5 times that of the deuterium atom of methanol- $d$. Moreover, it should be noted that the $\phi_{1}$ value (2.50) of poly(BCMO) cation is nearly equal to that (2.58) of polystyryl cation in copolymerizations of styrene-vinyl monomers. ${ }^{12}$ Taking the fact into account, we used the $\phi_{1}$ value as 2.50 in these copolymerization systems.

In order to calculate the $\delta^{\prime}$ value in Eq. 17, we plotted $\log \left(k_{12} / k_{11}\right) \quad\left(=\log \left(1 / r_{1}\right)-2.50 \log \right.$ $\left.\left(K_{D 2} / K_{D 1}\right)\right)$ evaluated from the $y$-armature in Figure 2 against $\Delta D_{i}(\mathrm{C}-\mathrm{O})$ of cyclic ethers (Figure 3). A linear relation through an origin was observed when $D_{i}(\mathrm{C}-\mathrm{O})$ of $\mathrm{BCMO}$ was taken as $63.0 \mathrm{kcal} / \mathrm{mol}$. The $\delta^{\prime}$ value is calculated to be 0.11 from the slope of the line.

The Tetrahydrofuran $\left(M_{1}\right)$-Cyclic Ethers $\left(M_{2}\right)$. As shown in Figure 4, no linear relationship was observed between $\log \left(1 / r_{1}\right)$ and $\log \left(K_{D 2} / K_{D 1}\right)$. This scatter is, of course, considered to be

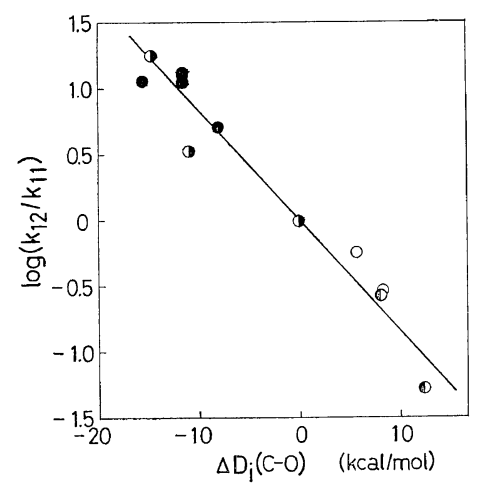

Figure 3. Relation between $\log \left(k_{12} / k_{11}\right)$ in cationic copolymerizations of cyclic ethers $\left(\mathrm{M}_{2}\right)-3$, 3-bischloromethyloxetane $\left(\mathrm{M}_{1}\right)$ and $\Delta D_{i}(\mathrm{C}-\mathrm{O})$ of cyclic ethers: three-membered ring; four-membered ring; $O$, five-membered ring; $\odot$, six-membered ring. 
caused by the difference in $D_{i}(\mathrm{C}-\mathrm{O})$ by the ring members of cyclic ethers.

On the other hand, it is considered that the electrophilic parameter $\phi_{1}$ depends not only on the electronic structure of cations, but also on the reaction conditions, i.e., the solvent, the catalyst, and the temperature. We assumed that the $\phi_{1}$ value of poly(THF) cation in the copolymerization systems is equal to that (2.50) of poly(BCMO) cation, catalyzed by the same catalyst at the same temperature, though in the different solvents. Thus, we obtained a linear relationship having the negative slope $\left(\delta^{\prime}=0.077\right)$

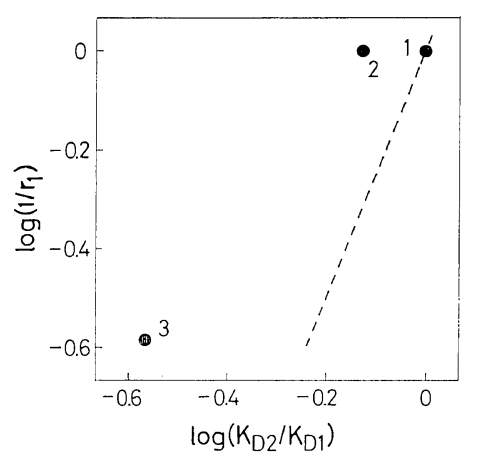

Figure 4. Relation between $\log \left(1 / r_{1}\right)$ in cationic copolymerizations of cyclic ethers $\left(\mathrm{M}_{2}\right)$-tetrahydrofuran $\left(\mathrm{M}_{1}\right)$ and $\log \left(K_{D 2} / K_{D 1}\right)$ of cyclic ethers $\left(\mathbf{M}_{2}\right)$ : (1) tetrahydrofuran; (2) 3, 3-bischloromethyloxetane; (3) epichlorohydrin.

A dotted line indicates a slope of 2.50 .

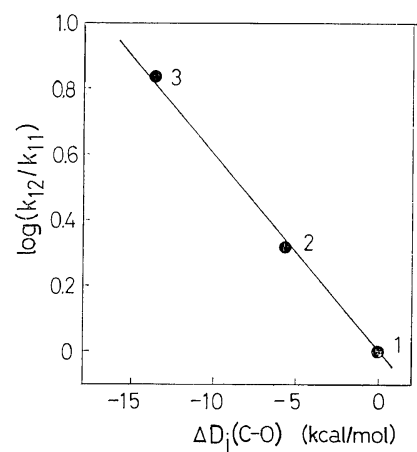

Figure 5. Relation between $\log \left(k_{12} / k_{11}\right)$ in cationic copolymerizations of cyclic ethers $\left(\mathrm{M}_{2}\right)$-tetrahydrofuran $\left(\mathrm{M}_{1}\right)$ and $\Delta D_{i}(\mathrm{C}-\mathrm{O})$ of cyclic ethers $\left(\mathrm{M}_{2}\right)$ : (1) tetrahydrofuran; (2) 2, 3-bischloromethyloxetane; (3) epichlorohydrin. through an origin between $\log \left(k_{12} / k_{11}\right)$ and $\Delta D_{i}$ $(\mathrm{C}-\mathrm{O})$ (Figure 5).

The 1,3-Dioxolane $\left(M_{1}\right)$--Cyclic Ethers and Formals $\left(M_{2}\right)$. We plotted $\log \left(1 / r_{1}\right)$ against $\log \left(K_{D 2} / K_{D 1}\right)$, as shown in Figure 6 . If the electrophilic parameter $\phi_{1}$ of poly(DOL) cation is assumed to be 2.50 and equal to that of poly(BCMO) cation, we can calculate $\log \left(k_{12} / k_{11}\right)$ to obtain the relation between $\log \left(k_{12} / k_{11}\right)$ and $\Delta D_{i}(\mathrm{C}-\mathrm{O})$. In Figure $7, D_{i}(\mathrm{C}-\mathrm{O})$ of $\mathrm{DOL}$ was taken as $61.6 \mathrm{kcal} / \mathrm{mol}$ so that a linear relation

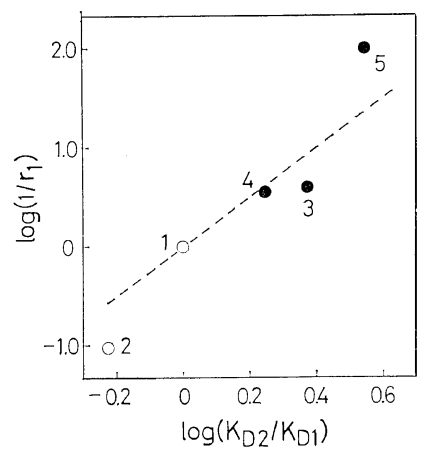

Figure 6. Relation between $\log \left(1 / r_{1}\right)$ in cationic copolymerizations of cyclic ethers and formals $\left(\mathrm{M}_{2}\right)$-1,3-dioxolane $\left(\mathrm{M}_{1}\right)$ and $\log \left(K_{D 2} / K_{D 1}\right)$ of cyclic monomers $\left(\mathrm{M}_{2}\right)$ : (1) 1, 3-dioxolane; (2) 4chloromethyl-1, 3-dioxolane; (3) tetrahydrofuran; (4) 3, 3-bischloromethyloxetane; (5) oxetane. A dotted line indicates a slope of 2.50 .

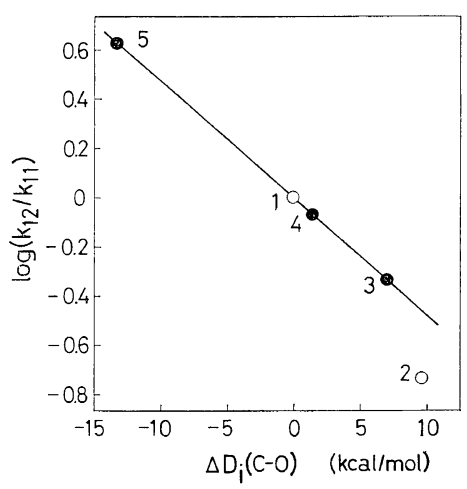

Figure 7. Relation between $\log \left(k_{12} / k_{11}\right)$ in cationic copolymerizations of cyclic ethers and formals $\left(\mathrm{M}_{2}\right)$-1,3-dioxolane $\left(\mathrm{M}_{1}\right)$ and $\Delta D_{i}(\mathrm{C}-\mathrm{O})$ of cyclic monomers $\left(\mathrm{M}_{2}\right)$ : (1) 1, 3-dioxolane; (2) 4-chloromethyl-1, 3-dioxolane; (3) tetrahydrofuran; (4) 3, 3-bischloromethyloxetane; (5) oxetane. 
Table IV. Calculated values and observed values of relative reactivities of cyclic ethers in cationic copolymerizations catalyzed by $\mathrm{BF}_{3} \cdot \mathrm{O}\left(\mathrm{C}_{2} \mathrm{H}_{5}\right)_{2}$ at $0^{\circ} \mathrm{C}$

\begin{tabular}{|c|c|c|c|c|c|c|c|c|}
\hline \multirow[b]{2}{*}{ Monomer $\left(\mathrm{M}_{2}\right)$} & \multicolumn{2}{|c|}{$\begin{array}{c}\text { 3, 3-Bischlorome- } \\
\text { thyloxetane }\end{array}$} & \multicolumn{2}{|c|}{ Tetrahydrofuran } & \multicolumn{2}{|c|}{ Epichlorohydrin } & \multicolumn{2}{|c|}{ 1, 3-Dioxolane } \\
\hline & Calcd ${ }^{a}$ & Obsd & Calcd $^{a}$ & Obsd & Calcd $^{\mathrm{a}}$ & Obsd & Calcd ${ }^{\mathrm{a}}$ & Obsd \\
\hline Ethylene oxide & 0.462 & 0.301 & 0.595 & & 0.927 & & 0.972 & \\
\hline Propylene oxide & 0.333 & 0.523 & 0.466 & & 0.798 & & 0.843 & \\
\hline 1-Butylene oxide & 0.400 & 0.523 & 0.533 & & 0.865 & & 0.911 & \\
\hline Epichlorohydrin & -0.463 & -0.398 & -0.332 & -0.585 & 0 & 0 & 0.046 & \\
\hline 3-Phenylpropylene oxide & 0.160 & 0.347 & 0.291 & & 0.623 & & 0.668 & \\
\hline Oxetane & 1.93 & 2.00 & 2.06 & & 2.39 & & 2.43 & 2.00 \\
\hline 2-Methyloxetane & 1.75 & 1.40 & 1.88 & & 2.21 & & 2.26 & \\
\hline 3, 3-Bischloromethyloxetane & 0 & 0 & 0.131 & 0 & 0.463 & 0.398 & 0.508 & 0.553 \\
\hline Tetrahydrofuran & -0.131 & 0.086 & 0 & 0 & 0.332 & 0.301 & 0.378 & 0.602 \\
\hline 2-Methyltetrahydrofuran & -0.249 & -0.114 & -0.119 & & 0.214 & & 0.259 & \\
\hline Tetrahydropyran & -0.266 & -0.180 & -0.136 & & 0.197 & & 0.242 & \\
\hline 2-Methyltetrahydropyran & -0.577 & -0.854 & -0.447 & & -0.115 & & -0.069 & \\
\hline
\end{tabular}

a Values calculated by Eq. 19 .

would be observed through an origin between them, and $D_{i}(\mathrm{C}-\mathrm{O})$ of 4-chloromethyl-1,3dioxolane (CDOL) as $68.9 \mathrm{kcal} / \mathrm{mol}$, by introducing a chloromethyl group. The scatter of CDOL from the straight line $\left(\delta^{\prime}=0.079\right)$ might be caused by the phenomenon of polymerization-depolymerization equilibrium, ${ }^{21,22}$ as will be described later.

In summarizing the above analytical results in cationic copolymerizations of cyclic ethers, we are led to the following two conclusions; (i) the monomer reactivities of cyclic ethers are

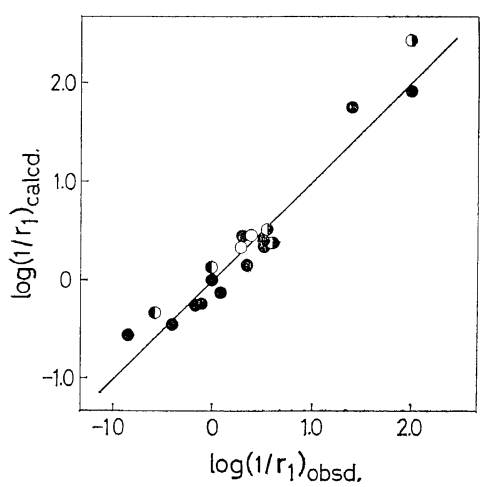

Figure 8. Comparison of the calculated values with the observed values of the relative reactivities of cyclic ethers $\left(\mathbf{M}_{2}\right)$ toward polymer cations $\left(\mathbf{M}_{1}\right)$ : - 3,3-bischloromethyloxetane; O, tetrahydrofuran; $\bigcirc$, epichlorofuran; $\mathbb{0}, 1,3$-dioxolane. quantitatively calculated by means of Eq. 18 (or 17) with two energetic terms of the free-energy changes of nucleophilic coordination and the radical dissociation energies of broken bonds, and (ii) the coefficients $\phi_{1}$ and $\delta^{\prime}$ of the energetic terms are 2.50 and 0.10 on the average, respectively. That is, we have

$$
\log \frac{1}{r_{1}}=-\frac{1}{2.3 R T}\left(2.50 \Delta \Delta G_{D}+0.10 \Delta D_{i}(\mathrm{C}-\mathrm{O})\right)
$$

The relative reactivities of various cyclic ethers were calculated for copolymerizations with various polymer cations and listed in Table IV. From the good agreement of the calculated values with the observed values (Figure 8), Eq. 19 is concluded to be useful for evaluating the monomer reactivities of various cyclic ethers in cationic copolymerizations.

\section{The Cationic Copolymerizations of 4-Chloro-} methyl-1, 3-dioxolane $\left(M_{1}\right)$-Cyclic Formals $\left(M_{2}\right)$

Using Eq. 17, we plotted $\log \left(1 / r_{1}\right)$ against $\log \left(K_{D 2} / K_{D 1}\right)$ and obtained a linear relationship through an origin, as shown in Figure 9. More noticeable is the fact that the value of the slope is 2.50. We cannot, however, make further quantitative conclusions, because of lack of information on $D_{i}(\mathrm{C}-\mathrm{O})$ of broken bonds of cyclic formals. 
On the other hand, it is well-known that the polymerization-depolymerization equilibrium is often observed in polymerizations of formals and lactones whose ceiling temperatures are considerably low; for example, 1, 3-dioxolanetrioxane $^{23}$ and $\beta$-propiolactone-3, 3-bischloro-

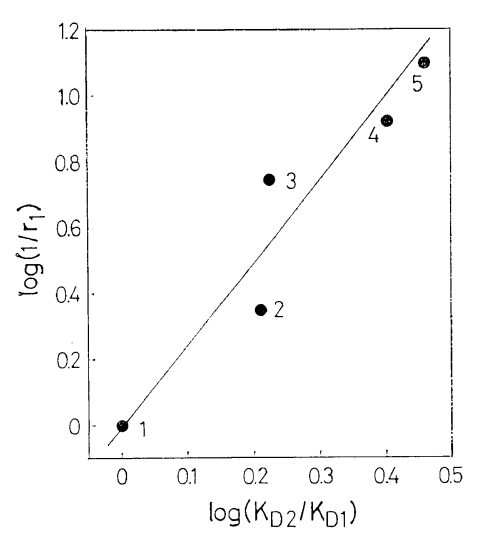

Figure 9. Relation between $\log \left(1 / r_{1}\right)$ in cationic copolymerizations of cyclic formals $\left(\mathrm{M}_{2}\right)-4$-chloromethyl-1, 3-dioxolane $\left(\mathrm{M}_{1}\right)$ and $\log \left(K_{D 2} / K_{D 1}\right)$ of cyclic formals $\left(\mathrm{M}_{2}\right)$ : (1) 4-chloromethyl-1, 3dioxolane; (2) 4-methyl-1, 3-dioxolane; (3) 1,3dioxolane; (4) tetramethylene formal; (5) 1, 3, 6trioxocane.

A straight line indicates a slope of 2.50 .

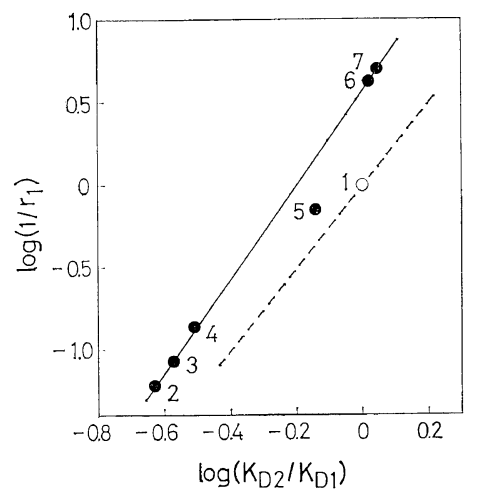

Figure 10. Relation between $\log \left(1 / r_{1}\right)$ in cationic copolymerizations of lactones $\left(\mathrm{M}_{2}\right)-3$, 3-bischloromethyloxetane $\left(\mathrm{M}_{1}\right)$ and $\log \left(K_{D 2} / K_{D 1}\right)$ of lactones $\left(\mathrm{M}_{2}\right)$ : (1) 3, 3-bischloromethyloxetane; (2) $\beta$-propiolactone; (3) $\beta$-methyl- $\beta$-propiolactone; (4) $\beta$-dimethyl- $\beta$-propiolactone; (5) $\gamma$-butyrolactone; (6) $\delta$-valerolactone; (7) $\varepsilon$-caprolactone.

A dotted line indicates a slope of 2.50. methyloxetane. ${ }^{24}$ It is said that such polymerizations do not, in general, follow the MayoLewis equation. However, taking the result in Figure 9 into account, and if it can be concluded that the nucleophilic-coordination power of monomer is the most important factor determining the monomer reactivity, then

$$
\log \frac{1}{r_{1}}=2.50 \log \frac{K_{D 2}}{K_{D 1}}
$$

\section{The Cationic Copolymerizations of 3,3-Bischloro-} methyloxetane $\left(M_{1}\right)$-Lactones $\left(M_{2}\right)$

The results of the copolymerizations of various lactones with poly(BCMO) cation are illustrated in Figure 10. A straight line, though not through an origin, was observed between $\log \left(1 / r_{1}\right)$ and $\log \left(K_{D 2} / K_{D 1}\right)$, except $\gamma$-butyrolactone. If the $\phi_{1}$ value of poly(BCMO) cation is 2.50 , we can calculate $\log \left(k_{12} / k_{11}\right)$ from the $y$-armature in Figure 10. However, further discussion cannot take place, because the radical dissociation energies of broken bonds have not been adequately reported.

\section{REFERENCES}

1. S. Iwatsuki, N. Takikawa, M. Okada, Y. Yamashita, and Y. Ishii, J. Polym. Sci., Part $B, 2,549$ (1964).

2. T. Saegusa, H. Imai, and J. Furukawa, Makromol. Chem., 56, 55 (1962).

3. S. Aoki, K. Fujisawa, T. Otsu, and M. Imoto, Kogyo Kagaku Zasshi (J. Chem. Soc. Japan, Ind. Chem. Sect.), 69, 131 (1966).

4. M. Okada, S. Iwatsuki, and Y. Yamashita, ibid., 68, 2466 (1965).

5. T. Tsuda, T. Shimizu, and Y. Yamashita, ibid., 68, 2470, 2473 (1965).

6. T. Tsuda, T. Shimizu, and Y. Yamashita, Makromol. Chem., 86, 304 (1965).

7. T. Kagiya, T. Kondo, and K. Fukui, Bull. Chem. Soc. Japan, 41, 1682 (1968).

8. T. Kagiya, T. Kondo, and K. Fukui, ibid., 41, 2473 (1968).

9. S. Aoki, Y. Harita, Y. Tanaka, H. Mandai, and T. Otsu, J. Polym. Sci., Part A-1, 6, 2585 (1968).

10. T. Kagiya, Y. Sumida, and T. Nakata, Bull. Chem. Soc. Japan, 41, 2239, 2247 (1968).

11. T. Kagiya, Y. Sumida, and T. Inoue, ibid., 41, 767, 773, 779 (1968). 
12. T. Kagiya and Y. Sumida, Polymer $J$, in contribution.

13. T. Kagiya, Y. Sumida, T. Inoue, and F. S. Dyachkovskii, Bull. Chem. Soc. Japan, 42, 1812 (1969).

14. T. Kagiya, Y. Sumida, and T. Inoue, ibid., 42, 2422 (1969).

15. T. Kagiya and Y. Sumida, Polymer J., 1, 137 (1970).

16. R. A. Ogg, Jr. and M. Polanyi, Trans. Faraday Soc., 31, 604 (1935).

17. K. Tarama, "Constants of Organic Compounds (Dai Yuki Kagaku, Bekkan 2)," M. Kotake Ed., Asakura Publishing Co., Ltd., Tokyo, 1963, p. 542 .

18. F. H. Seubolt, J. Chem. Phys., 22, 945 (1954).
19. F.S. Dainton, T. R. E. Devlin, and P. A. Small, Trans. Faraday Soc., 51, 1710 (1955); F.S. Dainton and K. J. Ivin, Quart. Rev. (London), 12, 61 (1958).

20. Y. Yamashita, T. Tsuda, M. Okada, and S. Iwatsuki, J. Polym. Sci., Part A-1, 4, 2121 (1966).

21. A. V. Tobolsky and G. D. T. Owen, ibid., 59, 329 (1962).

22. G. G. Lowry, ibid., 42, 463 (1960).

23. M. Kuçra and J. Pichler, Polymer, 5, 371 (1964).

24. Y. Yamashita, T. Asakura, M. Okada, and K. Ito, Preprint, The 18th Symposium of Polymer Chemistry, Tokyo, November, 1969, p 203. 